\title{
Redefining Human Communication Space Culture and Time in the Epoch of Internet Spatiality
}

\author{
Emmanuel Ezimako Nzeaka \\ School of Media \& Communication, Pan-Atlantic University, Lagos, Nigeria \\ *E-mail: enzeaka@pau.edu.ng
}

\begin{abstract}
The concepts of time, culture and communication have undergone rapid changes since the advent of the Internet. This text examined the influence of digital spatiality on our social life based on the three concepts. The new media have detached humanity from previous understandings of space, physical setting and culture. Therefore, the arrival of any new media systems advanced the boundaries of time-space and refinement in human manipulation of massages. This paper's thrust was to critically look at the dialectic between spatiality through time, culture, and communication to define how digital spatiality has truncated our conception of reality. The human perceptions of space have shifted from previous primordial physical location and limitations to a world illimitable boundary beyond out of the grasp of the authorities and natural elements. Time, space and culture have undergone rapid changes never experienced in human history. The finding's main conclusion was that advancement of the media brought about by the ubiquitous Internet had impacted heavily has adjusted our perception of living regulated by time-space constraints. The general context was that the Internet had abbreviated our conservative understanding of the concepts, challenging the perceptions of time, space and culture and constricted them as experienced in the epoch of Covid-19 in 2020 when humanity interconnected remotely.
\end{abstract}

KEYWORDS: Digital, Spatiality, Regulated, Time, Conception Culture.

DOI: $10.7176 /$ RHSS/11-10-07

Publication date:May $31^{\text {st }} 2021$

\section{INTRODUCTION}

This paper, taking cognisance of the ubiquitous nature of the Internet over our social milieu and the conception of interpretation of time, space, and culture, will examine the extent to which digital spatiality has influenced the perception of these social systems in human communication as reconstituted by digital spatiality. First, spatiality itself will be analysed as a whole to have a panoramic view of the holistic meaning of that word in the context of the paper. Spatiality is the advancement of implicit physical geography to straightforward interpretation through the building blocks of the digital universe when the vacuum is created, sustained and linked with each other throughout time based on the link and relationship cultivated over an interval with the inhabitants of the digital places. Related to this assertion, Gotved (2002) sees spatiality as traceable to social and metaphorical space in which contacts and the formulation of space and positioning with digital societies are negotiated. Space is a situation denoted by organism's semiotic independence, which is borne by the entity as an upshot of its capacity to abide by the world in the form of its unfolding boundary with its atmosphere (Ireland, 2018; Ali,2020). In a related definition, Pumain (2014) sees spatiality as one of the two main explanatory paradigms constructed by geography to explain the differentiation of use of the globe surface by human societies. It forms an interpretation utilising "horizontal" relations, which complement explanations based on "vertical" relations of societies with the diverse conditions and resources offered by natural environments (p. 1).

The Internet has complicated our conception of time and space by redefining how we manipulate them because they are also aspects of civilisation. Giddens (2018) further states that "employing time" leads to "employing space ", space is altered as the locale, and the dawn of modern life has removed the space from the place. The adjustment of our comprehension of space and time has created a new understanding of spatiality as it is now beyond physical space as we hitherto understood it. This created a condition whereby "the fragmentation and atomisation, the compartmentalisation and spatialisation of various regions of social life. . a least locally overcome" (Jameson,1988.p. 40). The spatiality has moved beyond physical expression to an extended context with the media's introduction, more significantly, the Internet. Soja (1989) indicates that space as a physical context has generated broad philosophical interest and lengthy discussions of its absolute and relative properties 
(a long debate, which goes back to Leibniz and beyond), its characteristics as environmental 'container' of human life, its objectionable geometry, and its phenomenological essences.

Nevertheless, this physical space has been a misleading epistemological foundation upon which to analyse human spatiality's concrete and subjective meaning (p.79). In essence, he points out that it has gone beyond physical understanding and traditional setting to cyberspace, which is beyond the physical regulation of humankind. Lefebvre (1991) also sees these as the subversion of the traditional space by emphasising that space, as it is understood now, can be called animate consequent on the proximity of the association between people, society and nature, insisting that occupied space gives a direct imprint to the interconnectedness of communal groups. Distance and time have become nebulous, indefinable and no longer a matter that can be grasped definitively in the old geographical sense. People now forge a union online without physical contact. Hasan,2013; Venter 2019) establishes this further by stating that cyberspace regulates physical movement with a touch or the rolling of a computer mouse. Some programmes synchronise with physical space. Through virtual reality, the user has a feeling of genuineness, the physical space, tactile, auditory, and visual authenticity that offers a sense of veracity.

Before the advent of the media, like printing, telegraph, radio, television and the ultimate Internet, spatiality was concrete because man stayed within his physical environment, which also regulated behaviour and categorised life according to status, sex, rank, family, age and other social determinants. Each society establishes space to specialise its ideas governed by ethics and criteria and its selection in accomplishments and practical capacity (Pumain, 2014). The arrival of the media redefined the traditional concept of time and distance. Similarly, McQuail (2010) points out that the advent of each new medium extended national boundaries beyond the previous reach of the old media by extending social boundaries and breaking down social compartmentalisation, hence developing the phrase "Global Village", where information is made liberal. This assertion connects to Myrowitz (1985) statement that the media's spatial nature has changed social experience by extending social spaces, which have access to information as gatekeeping has broken down. For instance, through broadcasting, humans can live on location and time beyond their physical surroundings and reality without face-to-face contact. In furtherance of this reality, Tally Jr (2013) points out that

Added to this, increased mobility and geographic anxiety were revolutionary technological advances that suppress the distance while also augmenting one's sense of place or displacement. What the railways, the steam engine, and the telegraph did to nineteenth-century space and time, air travel, telephones, television, and eventually space travel and orbiting satellites, computers, and the Internet did to spatiotemporal perception in the twentieth and twenty-first centuries (p. 14)

The dawn of the Internet, which expanded spatiality accelerated the pace of space by virtually shrinking the previous sphere of human contact by moving goods and services. This view is in corroboration with Sujavit (2015), who elucidates further that the current media technologies, which have become part of our life, have displaced the original face-to-face communication, occasioning in the extension of social contacts across social distances beyond human imagination, which has ensued in the elaboration of our space and time consequent of mediated communication. (Giddens,1994; Myrowitz, 1985; Thompson, 1995). Giddens states that the modern social merger has been standardised over time, consequently hastening the capacity of the multitude to communicate without hindrances. As a result, the nascent technology has squeezed spatiality. He notes that one can be at a particular location in the reality of life physically, but not in the same space. Therefore, with the arrival of technology, social institutions and mores that have sustained people for years have been" disembodied" from social dynamics through time and space complications. In furtherance of this argument, Ali (2020) states,

The language that can be used over the Internet affects a person's experience and choice of language expressions and affects the language itself in the way that it moves in agradual unification. Internet users, anywhere, try to use the same expressions regardless of where they are to communicate. This fact clarifies the idea of language globalisation (p. 102)

This condition has removed the human relationship from a particular setting and physical speed as we knew it has boiled down to the touch of a button. The place has already been" distanced", dispersed spatially and temporarily extended into the types of the spatial configuration of copresence or proximity. Before the advent of the media, people communicated person to person through physical mobility. The action reduces this engagement presently due to the alteration of temporal and physical space as the Internet's usage and other media 
devices have compressed time and space (Tsatsou, 2009). We can view this position from the supposition that space is now not conceptualised as a static territory but as a route with traffic bandwidth and linkages connected to a worldwide network with parallel network connections. Therefore, time, place, and culture occupied in a social dialectic intermingle present physical reality. This situation is that space acting independently of actors means nothing; until bodies and entities populate it with events happening within that distance.

Apart from regular communication, social media has further extended this spatiality beyond human comprehension. Social media apps such as Facebook and Twitter encompass a broad audience, thus stretching the limits of social boundaries. In this parlance, Agnew (2001) takes this argument further by pointing out that compression of time and space shows more of the role of speed rather than the importance of uninhabited setting, by the assertion on logistics means violating the previous code guiding the physical setting in terms of the faceto-face communication that deals with mutual respect and reciprocity. It has turned to organic media that disregard stratification or social rank empowering people from different contexts by raising consciousness on topics (Sujavit, 2015). Media spatiality makes for developing cultural space and ushers in the combination of diverse cultures entrenched in another space, which would not have been possible in our previous definition and understanding of space. The condition is a symbiosis between the physical and virtual world, being there and everywhere (Kangasluoma, 2006). Through the Internet, spatiality allows people to network with other people in the world's remotest areas and relate them to physical and social spheres. Rose (2004) elucidates the connection by observing that culture is now entirely remitted through new technologies. Spatiality is the extension of time and space beyond physical boundaries as we previously interpreted its understanding consequent on altering our sense of the past by the media, which has evolved into what we refer to as "Mediated Wordiness" (Thompson,1995). Our comprehension of the universe lies beyond our immediate environment, reshaped by mediated ways and means. This paper will be in three sections. The first section will deal with media theories; the second will be on media spatiality; the third will deal with time-space and media spat, quality; the fourth will handle the understanding of culture and spatiality. The last section will be the conclusion.

\section{Methodology}

This qualitative research was carried out via textual content analysis. Creswell $(2014$, p.49) writes that it is an iterated set of constructs formed into propositions or hypotheses that specify the relationship among variables. The investigation is a systematised approach to a phenomenon that yields results. Through a new hypothesis, facts are established, new hypotheses are considered, and current questions are answered. This research examines the impact of digital spatiality on time, space and culture in human communication; the investigation produced data from a thorough analysis of existing literature. The synthesis involved mapping and reviewing the relevant literature dealing with the study's core content issues. The analysis has helped identify the gaps in knowledge and the proper formulation, develop a conceptual framework and articulate the research methodology. The content analysis of the thesis explored broader literature on digital spatiality and the theoretical literary study on time, space and culture in human communication. It applied secondary qualitative conceptualisation, which centred on the combination of data mined through a detailed review of existing literature, including a critical examination of available written materials, journal articles, books, journals, magazines, internet-downloaded content on the enquiry of the subject.

\section{Literature Review}

\subsection{Theoretical framework}

Every research is rooted in a theoretical tradition that would form the foundation in approach to related literature. Theories are proven concepts to elucidate a set of principles upon which the action is based or a condition that clarifies an idea (Kudara, 2017). It is the backbone of any academic endeavour. This report will hinge on two popular mass media theories: The Media Dependency Theory propounded in 1976 by Sandra Bell Rokeach and Melvin De Fleur, and Technological Determinism Theory by Herbert Schiller in 1973. Media Dependency Theory states an internal link between the media, the audience and the social system. Accordingly, the three organs influence themselves and adjust from experience. The Media dependency theory model is relevant in this study because it represents the media's influence on the audience. 


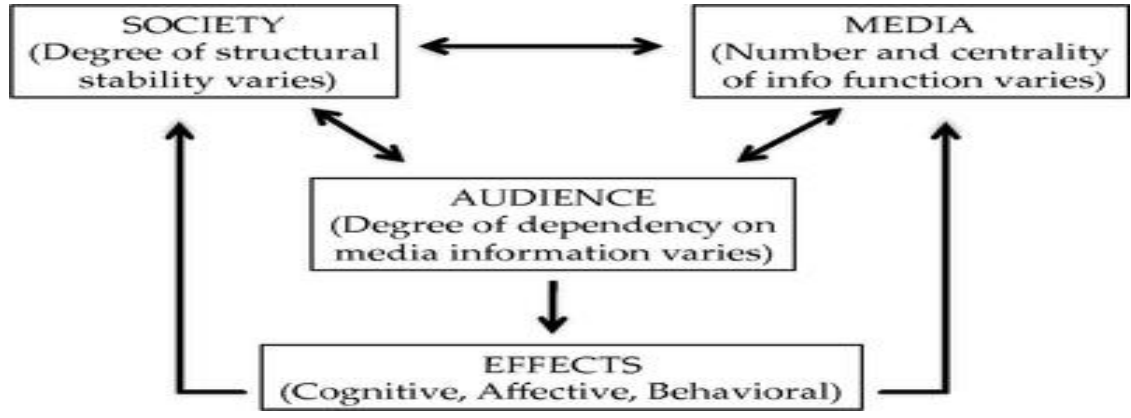

Fig. 1: Media dependency model

This dependency, which is a result of spatiality, will, in turn, affect the audience to change their attitude regarding the social system and belief. This condition develops a reliance syndrome on the medium's audience; the mass media, in turn, exploits the caving information to promote their agenda. This yearning becomes addictive when the media fulfil these demands regularly. With the growth of the Internet and the expansion of digital spatiality, the media dependence increases that location thrust beyond the demarcation lines of space to seek more information update. The audience depends on the media to get more data on personal needs like weather, intelligence, economic condition, online purchases, pandemics like Covid- 19 and even civilisation. These cravings will reduce whenever there is an option. This situation is in tandem with digital spatiality because the media goes beyond physical boundaries to influence the audience by providing their information needs.

The second premise is the Technological Determinism Theory, famous by Marshall Mc Luhan, though some researchers say it originated by Thornton Veblen (1857-1929). This theory points out that the kinetics of human communication regulate our existence by defining our culture because the progression of modern mass media has impacted our disposition. It asserts that life, right from the inception of humans, is synonymous with technology. The apparatus has regulated our conduct, shaping human dynamics and the way society conceives any situation. This condition implies that technology determines our disposition. A recent declaration insists that technology defines cultural, economic and social situations to aid that change. The stages of technology will influence life as our social arrangement will forever change due to prevalent technology. It has forever been a mutual relationship because as society determines technology, technology influences society for good or bad (Bailey, 2006). This situation is consequent in our self-absorbed tendency to extend social boundaries beyond human existence. (Ogburns,2014). This condition means that spatiality induces the influence of technology on our choices. These theories intricately connect with the theme of this paper; they will assist in propelling the comprehension of how the media has changed our understating of spa

\section{The concept of digital space}

This paper attempts to comprehend the significant role of digital spatiality in human communication and comportment, especially since the emergence of new media through the Internet. Digital spatiality relates to manipulating humans, media, location, space, and the new media have redefined the environment. In furtherance of this point, Soja (1989) notes that before the advent of the media, space was seen as the congregation of people in any specific habitation and their association is determined by sex, age, blood and mindset, sustained by categorised order. The action is an abbreviation of these aspects with the influx of the media. In the same vein, on this matter of substitution, Sujovit (2015) elucidates on this point by insisting that the original frontal communication has been broadened beyond the average human experience as boundaries to accommodate external variables and social connections. In other words, in media, space and place are defined beyond the physical context to extend to all influences, the reach of the Internet to the imagined physical space, something beyond the immediate into the cyberspace, to what McLuhan (1962) called the "Global Village". The global village has resulted in the compression of space and time beyond our immediate grasp by a computer network, thereby creating new geography (Graham, 1998). This issue has become possible in the fabrication of computer, 
space and social synchronicity dialogue simultaneously (Massey, 2005), thereby creating fuller engagement beyond our conception. These issues directly point to what Gotved (2002) called the topology of digital space. The triad of the digital space, place, and time built by individuals mediate from different settings, thereby drastically reducing space-time. This situation can be best illustrated vividly in Anderson (2006) classic on the manipulation of place and space to produce "Imagined Communities", where he points out that the Internet has created a diverse nation, totally not in consonance with the way we understand a political entity today, it is imagined virtual nation based on the organic union. He insists that" It is organic because the members of even the smallest nations will never know most of their follow-members, meet them, or even hear them, yet in the mind of each lives the image of their communion" (p. 49). This condition can be applied to the notion of spatiality not conceptualised when the piece was written. However, the relevance is not in question today as the new media has changes the fanatical nationalistic protection of nations' traditional boundaries to insist on its ideological stand to construct a truly global family as conceptualised by Benedict Anderson. After transformation, this situation induced the vibrancy of and the reformation of space and time by postmodern geography. This condition extends the point that new media has substituted real society with abstract communities beyond the government and private information hitherto regulations not made available to the people.

Activities can form a digital spatiality of people from a particular location through interconnected computers. It emanates from a location, and it moves from that place through the process of "transduction" to bring space into a manifestation for the interaction with internet communities. This condition can be manifested through space in a digital expression such as maps, texts, video games, Facebook, Twitter, Skype, WhatsApp and other related devices. These applications have relative influence as they counteract and change spatial boundaries (Lefevbre,1991). This situation is expressed in a place like the home or office, which globally shows interconnectedness through a computer network. Accordingly, Olivier (2011) insists that in these linkages, those activities assume contexts that are global and then take a web experience. This situation is what spatiality intends to show as it extends space beyond our physical environment. For example, space and place for an individual that is physically set in Nigeria through a Facebook page extend to Australia or Fuji Island while physically located in Nigeria, no matter the geography and different cultural setting.

In essence, digital spatiality has redefined the geographical definition of space and place by spreading globally through the Internet. By extension, the importance of space is no longer in our experience but regulated and determined by virtual reality, thereby creating liminal spaces that are at the same time familiar, yet strange, safe, yet overwhelming to the people who dominate that space. Consequently, in this process, spatialisation can become non-representational, thereby losing its community understanding and emotional attribute (Low, 2017) through penetration, accommodation and extension of traditional boundaries.

\section{Time and digital spatiality}

Before the advent of telecommunication, especially the Internet, human communication can only be achieved through mobility and physical contact. Time was localised and applied according to the setting and culture of a particular context. (Hassan \&Thomas, 2006; Thompson, 1995; Innis, 1991). The development of the primary form of communication resulted in the appropriation of time in the sense of spatial distance; messages be sent to a vast physical space quickly. This liberation of communication in cyberspace is possible due to the advancement in the devices' configuration to adopt social media and the Internet. The features that adorn the laptops and tabletop computers are now available in handheld devices. This situation facilitates digital exchanges speedily and conveniently. These devices control time as we understand it today, which have produced varied interpretations of time as we use and know it today (Soja,1996; Heidegger,1962; Lefebvre,1999; Oke, 2009). These changes are diverse from the way we used to understand time. This issue is a significant move because no longer understands the way we knew it in different cultures, and it is now interpreted in diverse ways, which include alteration, direction, and cyclical dynamics, as a measure of a system of social control or gendered reference to the application of time. (Oke). The significance is that time is no longer interpreted based on the culture of a particular place, the traditional and historical perspective that inculcates the past, present and future or the real clock time or by the seasons. All these are now impotent consequent on the spatiality of time in cyberspace. Sang-Hee et al. (2011) point out that cyberspace is removing time and space limitations, which means that the traditional application of time is under pressure from the Internet. This condition results in the 
compression of time in the way the user relates to it. This condition has fractured the geographical twenty-four hours given to all humans as individuals decide their own time. A user in Nigeria (night) can connect with a computer in Australia (evening) that links with another computer in Canada (morning), all working simultaneously in cyberspace unmindful of the time of time zones, as they conquer the deterrents of time and space. This infringement of the time barrier through digital spatiality is what Oke (2009) refers to as the annihilation of space that develops a compressed time that makes the world a smaller place. In the sustenance of this reality, the diffusion of time, its use as a tool of regulation, the inauguration of time in business, and policy adjusts with the developments in computer knowledge. The changes in time to an ecological function to be filled down to the microsecond - down to a level at which a period can be visualised as a continuum. In essence, time is interwoven with the system of human existence; it has become emancipatory.

This situation is noteworthy because the regulation, production and dissemination of messages are no longer at the leisure of institutions but in their place, correspondingly shared by all persons (Chen, 2012), through digital communication. Therefore, this issue works against our previous understanding of time and space as a unified whole as spatiality has reshaped temporal boundaries by creating cyber-mental space that brings non-linear information to all events occurring universally beyond time restriction. This situation is significant because with the freedom of time and space, the control of message production and dissemination is no longer a privilege possessed only by the church, state, and government, but instead, equally shared by all individuals. For example, according to (Innis, 2008), time was coded as a mandate by the church in the $14^{\text {th }}$ century to be strictly adhered to by people according to situations. This regulated culture and freedom of choice.

Gregory XIII introduced calendar reform in 1582 in which the cumulative inaccuracies of the year based on $365^{1 / 4}$ days were corrected, and October 5 reckoned as October 15. While the Catholic Church exercised a dominant control over time, other religions, Jewish and Protestant, asserted their rights, notably with the determination of holidays (p.71)

All these strict social controls were gradually eroded as technology advanced. Fuchs (2008) elucidates this condition by stating that cyberspace has adjusted space and time. When we send an e-mail, we do not have to be in the same physical space with the recipients; the procedure proceeds asynchronously. The actual compression and loss of time regulations in the media commenced with the advent of the commencement of the media. SangHee et al. (2011) observe "that the print media created, imaginative space, while TV created perceptual space. Besides, the Internet created cyberspace...These are closely related to time and space" (p.26).In other words, this distinction of humans from time was in phases as a new media advance, the limits of the previous one, contributing to the next change that will happen Mc Quail (2010). The new media narrows down our conception of time by overcoming the geographical limitations on the time application in digital spatial space. Therefore, our conception of time diversifies at many levels.

\section{Culture, digital spatiality, and human communication}

The concept of culture is universally accepted as a way of life of a group of people. It can also be a learnt behaviour; it is the totality of life. Culture is concentrated in a particular location that is carefully regulated by traditional practices, resistant to challenges by external influences. However, culture is dynamic; it brings changes about many circumstances internally or externally. Recently, culture has ceased to be compartmentalised, and it is under persistent pressure to adjust to fit the underlying forces of continuous change. The rapid development of spatialisation brought about by the new media and globalisation has liberalised culture beyond the confines of a particular location. Klepic (2018) captures this succinctly:

Culturally, digital has changed the way we identify with one another and form communities. While $20^{\text {th }}$-century consumers (users) bonded in close-knit neighbourhoods, today's target demographics gather together in far-flung global communities. They can quickly gather in chat rooms, YouTube communities, and online forums to share personal stories or provide advice. (p.2)

This diversity has made our understanding of culture and its practice complicated, by this means truncating our collective understanding of cultural communication. This section will, therefore, look at the influence of digital spatiality on culture and human communication. The etymology of human communication through signs, oral, and written tradition to print, electronics, and digital modes with the arrival of computers and the Internet in the 
1990s have a long history. Building upon the progression from quill pen, the printing press to cyberspace, each phase has challenges culture and our perception of space and time, which has changed them drastically. Human action has been compressed to reduce the engagement distance between humans, and the physical boundaries are no hindrances anymore. According to Chen (2012), the issue is vital as the government no longer control human activities regarding time, space regulations, dissemination and the production of the messages (culture) but equally shared universally. This agglomeration of publics shares many purposes by allowing people to congregate for social, political, cultural and civic causes (Boyed, 2011). This association aids people to link up with the world outside their immediate physical environment like internet structures and shapes their actions.

As a result of this issue, a new culture emerges that forms the behaviour of that particular group. Consequently, Internet had confronted the culture and our mental orientation, which does not align with the old model when communication was segmented because people inhabited isolated places and adapted from their forebears. These immediate experiences were handed down from generation to generation. The development of computers and the Internet has further broken down social distances, giving culture a broader interpretation by accommodating external variables. Therefore, creating what is regarded now as a third space whereby the residual culture and the media forge another hybrid culture considered a middle ground of the dual contact. The first and second spaces have worked out the hybridity of multiculturalism. In furtherance of this argument, Soja (1996) substantiates the matter by insisting that this space unification is the condition in which the first space assumes dimension in the concepts represented initially, and the second is the conception of ideas of the mind, a representation of ideas of imagined knowledgeable forms. The third space is the assortment of the real and imagined, which is the emergence of the new culture.

Similarly, Lefebvre (1991) conceives it as a negotiation between physical and mental dimensions, identifying three phases of manifestation: the perceived, the conceived and the material in a triadic conception. It is the combination of these phases that produces a virtual culture that is insulated from the primordial ethos. This condition has become possible through spatiality brought about by using media networks as an instrument to improve social skills and transform cultural understanding. Space and time no longer hinder humans as they can now spatially transcend these to adopt practices from people beyond their immediate experience. On another understanding, spatiality has extended the human capacity to communicate beyond the physical face-to-face, and it is no longer of physical contact to exchange information and ideas. Still, it now transcends natural boundaries through the Internet (Sujovit,2015). It now caters for ideas on culture as generated by many people from a diverse cultural background inclined to their way of life, thereby breaking the stranglehold of the traditional mode of communication as they develop their type of unique culture. The breaking of boundaries is consequent on the digital specialisation that has eroded old forms and "de-traditionalised" practices through the disembodying of old unions. Consequently, "culture as a passive placeholder of backward traits of traditionalism and as a relic of the past, was targeted through communication interventions" (Dutta, 2015, p.127)

Here, communication transcends culture by developing new social relationships through personalising experiences in an imaginary world, where users have evolved from information consumers to an information generator, transforming into a network society that is not limited by time or space. The progression is consequent on the convergence of the Internet and the influence of globalisation that has developed a diversified cultural identity in cyberspace that will redefine the traditional notion of cultural identity. This usher in a new culture in the areas of "temporality"," territoriality"," contrastively", "interactivity", and" multiplicity" (Belay, 1996).In other words, due to spatiality, the culture will be neither be a product of history nor will be it be localised. It will be a conglomeration of people's consciousness based on several decisions floating in cyberspace. Spatialized engagement no longer relies on the historical moment. It includes the otherness to the steady growth of spatial knowledge (Soja,1996). The continued growth of spatiality dilutes cultural communication; in this case, it impacts culture through diminishing occasioned by the entrant of the emerging culture and the transmogrification of the nascent one. Showkat (2015) goes further on the attenuation to say that

"Popular" culture is the media, products, and attitudes considered to be part of the mainstream of a given culture and the everyday life of ordinary people. It is often distinct from more formal conceptions of culture that takes into account moral, social, religious beliefs and values such as our earlier definition of culture. It can be asserted that there is a close relationship between mass media and the culture of people. Different mass media channels are interlinked with the culture of the place. Media narratives and discourses are created within different forms of texts and images 
that are complexly related to the cultural perceptions and practices of both those who produce and consume them (p.59)

As a result, the influence of media on culture and culture on media is symbiotic. It produces an unregulated hybrid culture that is not regulated by space, time and government fiat, except in totalitarian states like China.

According to Lefebvre (1991), the external and residual cultures fuse, but the new culture eventually dominates the system through spatiality. This assertion connects Meyrowitz (1985) observation that electronic media changes compartmentalisation, segmentation, age, gender, time, and social status to a novel interpretation. The media have broken down this discrimination and replacing it with emerging homogenous universal culture. McQuail's (2010) representation of the phases is adapted graphically.

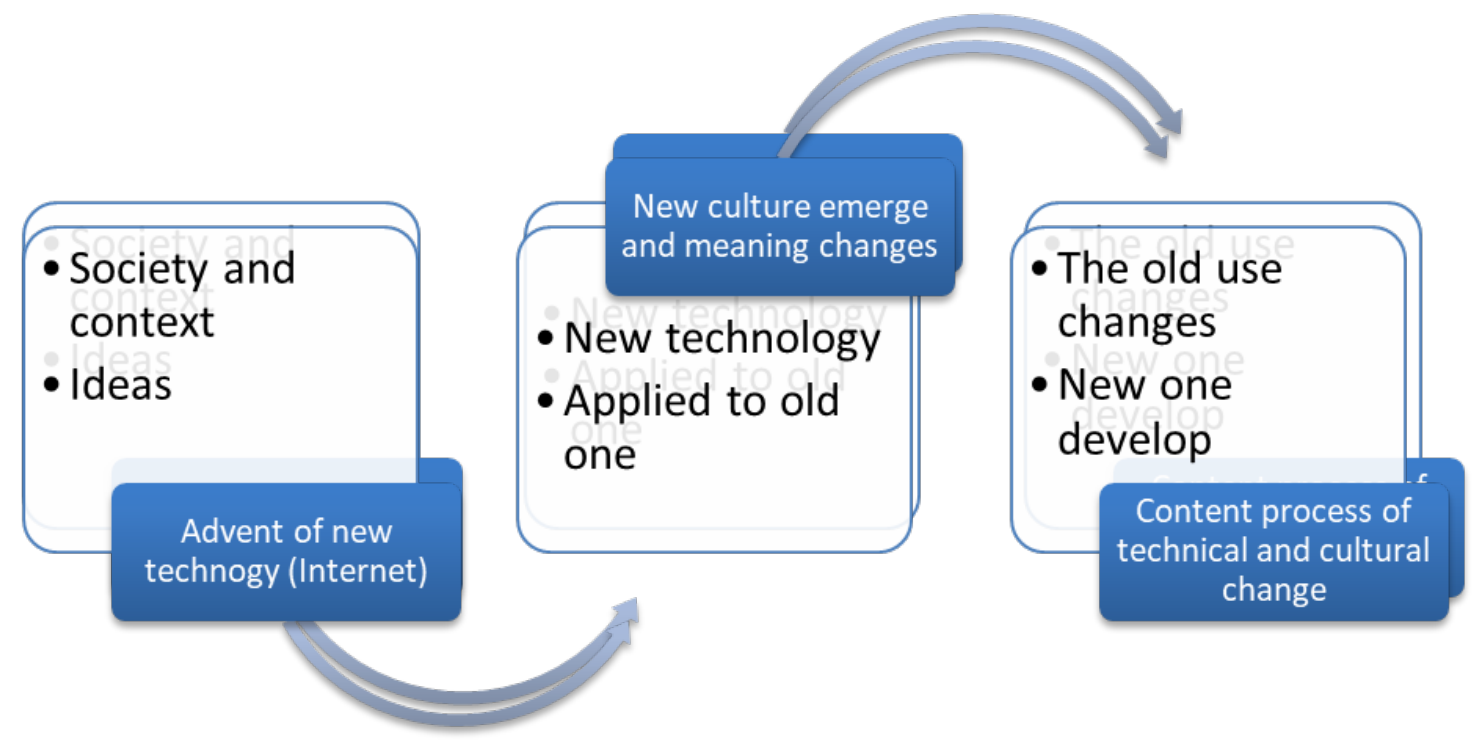

\section{g. 2: The interactive sequence of communication framework.}

The reduction of the geographical space through spatiality impacted communication and culture, which has resulted in the removal of people from the old communication system that regulated spatial movement without regards for extended geography and different cultural contexts.

\section{Discussion and Conclusion}

\subsection{Discussion}

The search determined the influence of digital spatialisation on the concept of time, culture and communication, investigating how these have redefined with the coming of digital civilisation. The first part considered the concept of spatiality, and the second part assessed digital spatiality. The third part looked at the relationship between time and digital speciality, and the last section evaluated culture and digital spatiality. All sections highlighted the changes that passed through the influence of digital spatiality. It was clear that throughout history, new technologies have adjusted life as posited in the Technology Determinism Theory by Thornton Veblen (1857-1929) and popularised by Marshall Mc Luhan and the Media Dependency Theory by Sandra Bell Rokeach and Melvin De Fleur that humans and technology/media as mutual and symbiotic. The computer has conquered spatial constraints because it takes the users closer to reality where time, culture and space are mingled and have created "Death -of- distance" (Tronos \& Nijkamp, 2012, p.1). Therefore, the media develop a bulk message that encompasses all, and this condition has reshaped human consciousness. The Internet is not just the connectivity of computers; only this circumstance has strained the dynamic techno-social practice that has broken down distance, time and culture as we knew it. A new spatial reality that has ushered in new 
possibilities has been formed in its place. Consequently, "It has enlarged international scientific collaboration" (Schlesinger, 2020). Again at this time, COVID-19 pandemic era as Elhers (2020) points out that

Social media is an exclusively forward-moving industry. Innovators are constantly pivoting, building and imagining new possibilities for the future of platforms. And as we progress into the remainder of 2020, I am confident that all pandemic-fueled, social change-inspired tools and platforms will stay - if not grow. (p.1)

The pandemic era has further broken down the social distance between the correspondents and citizenry. It further eroded cultural exclusivity that started with the Internet's evolution, as most of us worked in the pandemic's height without any cultural or space hindrances.

\subsection{Recommendations}

As it stands today, technology has reshaped the human concept of time, space and culture. With the twenty-four-hour clock times, our comprehension of space and culture are now beyond the physical. It is directly at the behest of a digital specialist to determine the sender/recipient disposition and social behaviour. This relationship has defined the human societal universe. This research recommends that:

1. Consequently, humans should adjust to the new challenges brought about by this development by adopting positive tenets from another culture.

2. There should be government regulations on the application of the Internet to protect the weaker nations from the dominance of residual culture from the emergent traditions.

3. The common interest of weak nations should be protected against the dominance of the stronger nations through national legislation and media policies.

\subsection{Limitations and future directions of research}

The research had a few limitations because it concentrated only on limited areas of human concern that the new media have negatively impacted and positively at the neglect of other vital areas of human endeavour beyond the conception of time, space, and culture. The new territories of concern for future research would be how other areas of human apprehension are adjusting to the new media challenges and the impact on society in the everevolving human situation driven by the Internet.

\section{References}

Agnew, J. (2015).The new global economy time-space compression, geopolitics and uneven global development. Retrieved from www.researchgate .net

Anderson, B. (1991).Imagined communities: Reflections on the origin and spread of nationalism.London: Verso.

Ali,B.W.(2020).The use of capital CMC expression in the non-capital cities as a sign of language unification. International Journal of Linguistics, Literature and Translation 2 (4),100-109)

Belay, G. (1996). The (Re)construction and negotiation of cultural identities in the age of globalisation. In H. B. Mokros (Ed.), Interaction \& identity (pp. 319-346). New Brunswick, NJ: Transaction.

Boyed, D. (2011).Social network sites as network publics: Affordable dynamics and implications. In Papacharissi, Z.(Ed.). Identity, community, and culture on social network. London: Routledge.

Chen, G. (2012). The impact of new media on intercultural communication in a global context.China Media Research 8 (2) ,1-10. 
Dutta, M.(2015).Decolonising communication for social change: A cultural centred approach.Communication Theory. $25,123-143$.

Drago, E., 2015, 'The effect of technology on face-to-face communication', The Elon Journal of Undergraduate Research in Communications 6,(1), 13-19

Elhers, K.(2020).Three ways 2020 has changed the social media landscape. Retrieved from forbes.com

Fuch, C.(2008).Social Theory of the information age. London: Routledge.

Giddens, A.(2018).Consequences of modernity. Stanford: Stanford University Press.

Gotved, S.(2002). Spatial dimensions in online communities. Space and culture. 1, (4), 405-414.

Graham, S.(1998).The end of Geography or the explosion of space? Conceptualising space, place and information technology. Progress in Human Geography 22,(2) 165-185.

Hasan, S. (2013).Mass communication: Principles and practice.New Delhi: CBS Publishers.

Hassan, R \& Thomas, J. (2006).The new media theory reader. Berkshire: Open University Press.

Heidegger, M. (1991).The concept of time (Mc Neill, W. Trans.).Oxford: Blackwell.

Innis, H.(2008).The bias of communication. Toronto: University of Toronto Press.

Ireland, T. (2015). The Spatiality of Being. Biosemiotics. 8:381-401.

Jameson. (2008). The political unconscious: Narration as a socially symbolic act.New York: Cornell University Press.

Kangasluoma, S.(2006).Mobile culture: culture in virtual places.Retrieved from www.on the-move.org

Kleptic, J. (2018). The digital age has changed the culture and business management. Retrieved from http://arcompany.co

Kudara, C.(2017). How theories are used in psychology: Retrieved from www.katikore.fi

Lefebvre, H. (1991).The production of space. Oxford: Blackwell.

Low, S.(2017). Spatialising culture: The ethnography of space and place. New York: Routledge.

Mc Quail. (2010). Mass communication theory. London: Sage Publications.

Myrowitz, J. (1985).No sense of place: The impact of electronic media on social behaviour.Oxford: Oxford University Press.

Ogbuns, S.(2014).Technological determinism. Retrieved from www.revolvy.com

Oke, N. (2009). The globalisation of time and space Temporal and spatial considerations in discourses of globalisation. International Political Sociology. 3, 310-326.

Olivier, A.(2017).Understanding Place. In Janz, B.B (ed). Place, space and hermeneutics. Switzerland: Springer.

Pumain, D.(2014).Spatiality. Retrieved from www.hypergeo.eu

Rose, G.( n.d).Rethinking the geographies of cultural 'objects' through digital technologies: Interface, network and friction. Retrieved from www.researchgate.net/publication

Sang -Hee, K., Kyung-Ho, H.,\&Do Hyun, J.(2011).Time and space perception in media platforms.Proceedings of the Media Ecology Association. 12 Retrieved from www.media-ecology.org/

Schlesinger,P.(2020).After the post public spere.Media Culture and Society.42,7-8,1545-1563. 
Showkat,N. (2015), media and culture:A theoretical perspective of the inter-relationship.Retrieved from Researcgate.net.

Soja, E. (1999).Thirdspace: Journey to Los Angeles and other real and imagined places. Oxford: Blackwell Publishers.

Sujovit, B. (2015). Transcendence through social media. Journal of Media and Communication Studies, 8(3), 25 30 .

Talbot, H \& Gillespie, A.(2008).Policy and the rural information society. In Rusten, G \& Skerrat, S (Eds).Information and Communication technologies in rural society: Being rural in a digital age.London: Routledge.

Tally, R.T. (2013). Spatiality.London: Routledge.

Thompson, J.B. (1988).The media and modernity: A social theory of the media. Oxford: Blackwell Publishers.

Tranos, E \&Nijkamp, P.(2012). The death of distance revisited: cyber place, physical and relational proximitieskag. Retrieved from www.dspace.ubvu.vu.nl/bitstream/handle/1871/38500/12066.pdf?

Tsatsou, P. (2009) Re-conceptualising time and space in the era of electronic media and communications.Journal of Media and communication 1, 11-32

Venter, E., 2017, 'Bridging the communication gap between generation Y and the baby boomer generation. International Journal of Adolescence and Youth 22(4), 497-507. 